\title{
Effect of diffusion losses on the size growth of nanoparticles by coagulation
}

\author{
M. Alonso $(*)$
}

\begin{abstract}
The size growth rate of aerosol particles by Brownian coagulation is significantly reduced in the case of nanometer-sized particles, for which deposition losses are extremely high. A simplified model, assuming that the coagulation rate constant and the deposition loss rate constant are both independent of particle size, is proposed. The size growth rate reduction predicted by the model is in very good agreement with the experimental results.
\end{abstract}

Keywords: Aerosol. Coagulation. Diffusion losses.

\section{Efecto de las pérdidas por difusión en el crecimiento de nanopartículas por coagulación} Resumen velocidad de crecimiento de partículas de aerosol por coagulación browniana se reduce
considerablemente en el caso de nanopartículas, para las que las pérdidas por difusión son
extremadamente altas. Se propone un modelo simplificado en el que las constantes de velocidad,
tanto de coagulación como de pérdida por difusión, se suponen independientes del tamaño de
partícula. Las predicciones del modelo están en buen acuerdo con los resultados experimentales.

Palabras clave: Aerosol. Coagulación. Pérdidas por difusión.

\section{INTRODUCTION}

Most of the processes of particle formation by aerosol methods consist in an initial stage of homogeneous nucleation of precursor monomers in gas phase followed by rapid coagulation of particles with either the remaining monomers or other particles (1-3). The particle size attainable mainly depends on the supersaturation ratio of the condensing vapor and on the aerosol residence time in the reactor. As coagulation proceeds, particle concentration decreases and, hence, the coagulation rate also decays with time. If the residence time is sufficiently long, a certain steady-state particle size distribution is attained.

However, in practice, particles undergoing Brownian coagulation also diffuse to the reactor walls and are lost by deposition onto them. Specially in the initial stages of the gas-to-particle conversion process, when the particle size is still

(*) Centro Nacional de Investigaciones Metalúrgicas, CENIM (CSIC), Avda. de Gregorio del Amo, 8. 28040-Madrid (España). very small (high diffusitivity), diffusion losses to the wall are markedly large. This additional particle concentration depletion causes a further reduction of the size growth rate and, as a result, the final attainable particle size is much smaller than in the ideal case described above. In the present investigation, the dramatic effect of diffusion losses on particle size growth rate is examined theoretically and experimentally.

\section{THEORY}

Under the assumption of size-independent coagulation rate constant $K$ and diffusion loss rate constant $\delta$, the rate of change of the number concentration $n_{j}$ of particles composed of $j$ monomers can be written as

$$
\frac{d n_{\mathrm{j}}}{d t}=1 / 2 K \sum_{i=1}^{j-1} n_{i} n_{j-i}-K N n_{j}-\delta n_{j}
$$

where 


$$
N(t)=\sum_{j=1}^{\infty} n_{j}(t)
$$

is the total particle number concentration at time $t$. The analytical solution of equation [1] for the general case of an initial size-distributed particle population can be found as explained elsewhere (4), but it is not needed for our present purpose. Summing up [1] to all sizes one finds

$$
\frac{d N}{d t}=-1 / 2 K N^{2}-\delta N
$$

This equation can be easily solved to yield

$$
N=\frac{N_{0} \mathrm{e}^{-\delta t}}{1+\frac{K N_{0}}{2 \delta}\left(1-\mathrm{e}^{-\delta t}\right)}
$$

where $N_{0}$ is the total particle number concentration at time $t=0$. The average particle size at time $t$, $j_{a v}(t)$, can be found from the mass balance conservation equation

$$
j_{a v}(t) \cdot N(t)=N_{0} \mathrm{e}^{-\delta t}
$$

where $\mathrm{e}^{-\delta t}$ is the total particle penetration after a time interval $t$. From the last two equations one finally arrives at

$$
j_{a v}(t)=1+\frac{K N_{0}}{2 \delta}\left(1-\mathrm{e}^{-\delta t}\right)
$$

or in terms of the mean volume diameter $D_{v}$ :

$$
D_{v}^{3}=j_{a v}(t) \cdot D_{1}^{3}=D_{1}^{3}\left[1+\frac{K N_{0}}{2 \delta}\left(1-\mathrm{e}^{-\delta t}\right)\right]
$$

where $D_{1}$ is the diameter of the unit particle $j=1$ (monomer).

When diffusion losses are neglected, the corresponding result is

$$
\left.D_{v}^{3}\right|_{\delta \rightarrow 0}=D_{1}^{3}\left(1+1 / 2 K N_{0} t\right)
$$

Thus one sees that if diffusion losses are neglected the particle volume increases linearly with time. The effect of diffusion losses is to reduce the particle growth rate and, furthermore, it makes the volume-equivalent diameter to attain the asymptotic value

$$
D_{v \infty}^{3}=D_{1}^{3}\left(1+\frac{K N_{0}}{2 \delta}\right) .
$$

This last result is not strictly correct: much before the size $D_{v \infty}$ is attained, all the particles have been lost to the walls!

\section{EXPERIMENTAL}

The experimental set-up is shown in figure 1 . $\mathrm{NaCl}$ aerosol particles generated by a conventional evaporation-condensation method were let to flow through a coagulation chamber. The size distribution of the particles was then determined by a DMA-CNC system (Differential Mobility Analyzer - Condensation Nucleus Counter).

Experiments were done at two aerosol flow rates, 2 and $6 \mathrm{~L} / \mathrm{min}$, through the coagulation chamber. The air flow rate through the evaporationcondensation generator was always $6 \mathrm{~L} / \mathrm{min}$, thus in the experiments of aerosol flow rate of $2 \mathrm{~L} / \mathrm{min}$ through the coagulation chamber, part of the aerosol $(4 \mathrm{~L} / \mathrm{min})$ was purged just before the chamber inlet. The aerosol flow rate through the particle size measurement system was kept constant at $2 \mathrm{~L} / \mathrm{min}$, irrespective of the flow rate through the coagulation chamber, in order to have the same amount of particle losses after the chamber.

The mean aerosol residence time in the coagulation chamber was also modified by changing its length. The chambers were $13 \mathrm{~mm}$ ID copper tubes of lengths 4,8 and $24 \mathrm{~cm}$. The combinations of flow rate and chamber length gave five different mean aerosol residence times : 0.053, 0.106 and $0.318 \mathrm{~s}$ for $6 \mathrm{~L} / \mathrm{min}$; and $0.159,0.318$ and $0.954 \mathrm{~s}$ for $2 \mathrm{~L} / \mathrm{min}$. The experiments with the same mean residence time $(0.318 \mathrm{~s})$ but different aerosol flow rates ( 2 and $6 \mathrm{~L} / \mathrm{min}$ ) were selected as a means to check the reliability of the experimental set up: these experiments should yield the same results.

The generator was operated at two different temperatures, 660 and $690{ }^{\circ} \mathrm{C}$, so as to have two different aerosol size distributions at the coagulation chamber inlet.

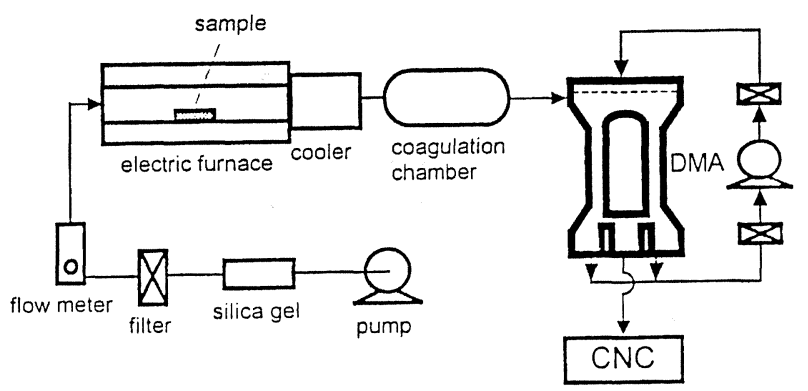

Fig. 1.- Experimental set-up.

FIG. 1.-Montaje del equipo experimental. 
The DMA was similar to the original Vienna design of Winklmayr et al. (5), with length $7.9 .5 \mathrm{~mm}$, and radii 28 and $33 \mathrm{~mm}$. The aerosol flow rate (inlet = sampling) was $2 \mathrm{~L} / \mathrm{min}$, and the sheath air flow rate (inlet $=$ excess) was $38 \mathrm{~L} / \mathrm{min}$. Concentrations were measured with a mixing type $\mathrm{CNC}$.

\section{RESULTS AND DISCUSSION}

The results obtained in the experiments with generator temperatures of 660 and $690{ }^{\circ} \mathrm{C}$ are shown in figure 2 , along with the theoretical curves calculated with eqs. [7] and [8]. The fitting of the experimental data to eq. [7] yielded values of $\delta=$ 2.03 and $2.27 \mathrm{~s}^{-1}, K N_{0}=3.33$ and $5.91 \mathrm{~s}^{-1}$, and $D_{1}=$ 4.28 and $6.88 \mathrm{~nm}$, for 660 and $690^{\circ} \mathrm{C}$, respectively. These values of $K N_{0}$ and $D_{1}$ were also used to calculate the average particle size for no diffusion losses, eq. [8].

The first thing to note is the good agreement between the results obtained in the experiments of equal residence time $(0.318 \mathrm{~s})$ in the coagulation chamber with different aerosol flow rates (for 660 ${ }^{\circ} \mathrm{C}$ the two experimental points coincide). This proves the correctness of the experimental method and the reliability of the results.

If diffusion losses are neglected, the particle volume should increase linearly with time (dotted line). However, as figure 2 clearly shows, the actual particle size growth rate (solid line) is significantly smaller than that ideally expected in the absence of diffusion losses.

These results show that, except at the very beginning of the process, where the extent of diffusion losses is not yet noticeable, particle diffusion loss to the reactor walls exerts a drastic effect on the ultimate particle size attainable. In spite of this strong influence, diffusion losses to the wall have not been considered so far in the mathematical modelling of aerosol reactors.

\section{CONCLUSIONS}

The experiments reported in this paper have shown that particle diffusion losses to the walls should be included in the analysis and modelling of gas-to-particle conversion processes in aerosol reactors. A simple mathematical model, using sizeindependent coagulation and diffusion loss rate constants, has been proposed which predicts with great accuracy the experimentally observed particle size growth rate.

\section{REFERENCES}

(1) Gurav, A., Kodas, T., Pluym, T. and Xiong, Y. Aerosol Sci. Technol., 19 (1993) : 411-452.
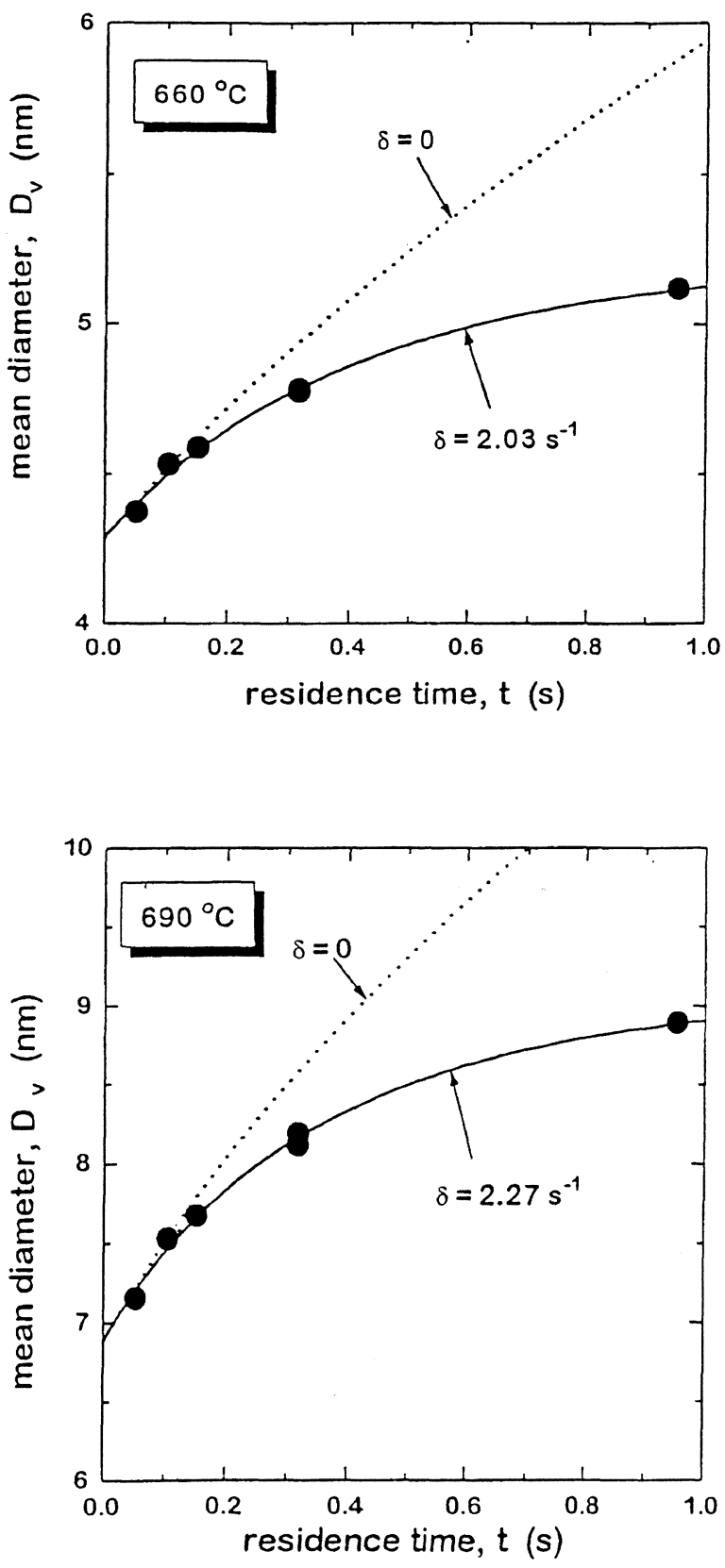

FIG. 2.- Particle size growth time for the experiments with generator temperatures of a) 660 ${ }^{\circ} \mathrm{C}$ and b) $690{ }^{\circ} \mathrm{C}$.

FIG. 2.- Crecimiento del tamaño de partícula en función del tiempo para temperaturas del generador de a) $660^{\circ} \mathrm{C}$ and $\left.b\right) 690^{\circ} \mathrm{C}$.

(2) Wu, M.K., Windeler, R.S., STEINER, C.K.R., Börs, T. and Friedlander, S.K. Aerosol Sci. Technol., 19 (1993) 527 548.

(3) Kusters, K.A. and Pratsinis, S.E. Powder Technol., 82 (1995) 79-91.

(4) Alonso, M., Higuchi, M., Nomura, T. and KousaKa, Y. $J$. Aerosol Sci., submitted.

(5) Winklmayr, W., Reischl, G.P., Lindner, A.O. and Berner, A. (1991) J. Aerosol Sci. 22, 289. 